\title{
Cryogenic Tank Modeling for the Saturn AS-203 Experiment
}

\author{
Gary D. Grayson, ${ }^{*}$ Alfredo Lopez, ${ }^{\dagger}$ and Frank O. Chandler, ${ }^{*}$ \\ The Boeing Company, Huntington Beach, California, 92647 \\ Leon J. Hastings ${ }^{\S}$ \\ Alpha Technology, Inc., Huntsville, Alabama 35812 \\ Stephen P. Tucker ${ }^{\mathrm{T}}$ \\ NASA Marshall Space Flight Center, Huntsville, Alabama 35812
}

\begin{abstract}
A computational fluid dynamics (CFD) model is developed for the Saturn S-IVB liquid hydrogen (LH2) tank to simulate the 1966 AS-203 flight experiment. This significant experiment is the only known, adequately-instrumented, low-gravity, cryogenic selfpressurization test that is well suited for CFD model validation. A 4000-cell, axisymmetric model predicts motion of the $\mathrm{LH} 2$ surface including boil-off and thermal stratification in the liquid and gas phases. The model is based on a modified version of the commerciallyavailable FLOW-3D software. During the experiment, heat enters the LH2 tank through the tank forward dome, side wall, aft dome, and common bulkhead. In both model and test the liquid and gases thermally stratify in the low-gravity natural convection environment. LH2 boils at the free surface which in turn increases the pressure within the tank during the $\mathbf{5 3 6 0}$ second experiment. The Saturn S-IVB tank model is shown to accurately simulate the self pressurization and thermal stratification in the 1966 AS-203 test. The average predicted pressurization rate is within $4 \%$ of the pressure rise rate suggested by test data. Ullage temperature results are also in good agreement with the test where the model predicts an ullage temperature rise rate within $6 \%$ of the measured data. The model is based on first principles only and includes no adjustments to bring the predictions closer to the test data. Although quantitative model validation is achieved for one specific case, a significant step is taken towards demonstrating general use of CFD for low-gravity cryogenic fluid modeling.
\end{abstract}

\begin{tabular}{|c|c|c|c|}
\hline \multicolumn{4}{|c|}{ Nomenclature } \\
\hline$\Delta \mathrm{X}$ & $=$ smallest radial cell size, in & $P_{\text {ULL, END }}$ & $=$ end ullage pressure, psia \\
\hline$N_{X}$ & $=$ number of $x$ cells & $t_{\text {RUN }}$ & $=$ simulation run time, hrs \\
\hline $\mathrm{N}_{\mathrm{Z}}$ & $=$ number of $z$ cells & $T_{\text {LIQ, END }}$ & $=$ end liquid temperature, $\mathrm{R}$ \\
\hline$N_{\text {TOT }}$ & $=$ total number of cells & $\mathrm{T}_{\text {ULL END }}$ & $=$ end ullage temperature, $\mathrm{R}$ \\
\hline
\end{tabular}

\section{Introduction}

$\mathrm{O}$ N. July 5, 1966 the Saturn IB AS-203 vehicle was launched to provide performance verification of the second stage (S-IVB) propellant control and engine chill-down systems. This experimental flight produced valuable data concerning cryogenic fluid behavior and heat transfer in low-gravity environments. It is the only known lowgravity cryogenic test with adequate instrumentation for model validation. Due to the high costs of testing cryogens in space, the capability to accurately model low-gravity cryogenic propellant tank dynamics and heat transfer is a critical enabler for cost effective space exploration. The closed tank phase of the 1966 S-IVB flight experiment is used, therefore, to determine the accuracy of a new computational fluid dynamics modeling approach

\footnotetext{
*Associate Technical Fellow, Propulsion \& Cryogenic Technologies, 5301 Bolsa Ave/H012-2B201, Senior Member

${ }^{\dagger}$ Associate Engineer/Scientist, Propulsion \& Cryogenic Technologies, 5301 Bolsa, Ave/H012-2B201

¥Director, Propulsion \& Cryogenic Technologies, 5301 Bolsa Ave/H012-2B201, Associate Fellow

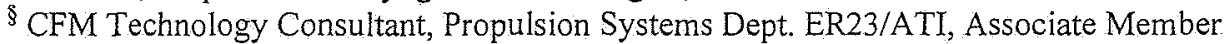

${ }^{\Uparrow}$ Lead, Cryogenic Fluid Management Technology Team, Propulsion Systems Dept. ER23
} 
The S-IVB LH2 tank has a diameter of $22 \mathrm{ft}$ and shares a common bulkhead with the liquid oxygen (LO2) tank that is positioned below the LH2 tank; see Fig. 1 from Ref. 1. The tank is approximately $37-\mathrm{ft}$ long and is instrumented with 40 wall temperature sensors distributed along the common bulkhead, cylindrical side wall, forward dome, and aft dome. Instrumentation rakes extending into the tank provide measurements of the liquid and gas temperatures within the vessel.

The closed fuel tank experiment was performed toward the end of the AS-203 S-IVB flight when $16,000 \mathrm{lb}$ of LH2 remained in the SIVB stage. The goal of the experiment was to measure the self-pressurization rate of the LH2 tank while in the low-gravity environment of Earth orbit. The LO2 tank ullage thrusters provided settling acceleration to maintain aft-settled LH2, and the net acceleration to the vehicle decreased during the test from an initial value of $3.7 \mathrm{E}-4 \mathrm{~g}$ to $0.8 \mathrm{E}-4 \mathrm{~g}$. As reported in the Ref. 1 document from 1967 the fuel tank pressurized from 12.4 psia to 37.7 psia over the 5360 -seconds experiment; this equals an average low-gravity pressurization rate of $17.0 \mathrm{psia} / \mathrm{hr}$.

Two models were developed during the Saturn program to predict the low-gravity pressurization rate for the SIVB tank. One assumed liquid heating only while the other input energy into both the liquid and gas phases. As shown in Ref. 1 both of these previous analytical methods from 1967 under predicted the low-gravity pressurization rate. It is the aim of the present research to apply a modern computational fluid dynamics approach to the AS-203 experiment to improve upon the previous models' capabilities.

\section{Approach}

\section{A. FLOW-3D Software}

FLOW-3D is a general Navier-Stokes equation solver with an extensive history in liquid slosh and heat transfer modeling (Refs. 2-11) thus making it a suitable point of departure for a two-phase cryogenic tank model. Various options in the governing equations may be enabled or disabled in FLOW-3D depending on the physics important to the problem. In the present cryogenic tank analysis a $2^{\text {nd }}$ order momentum equation is used with a $1^{\text {st }}$ order energy approximation. The free surface, wall shear, surface tension, and $k-\varepsilon$ turbulence model options are all enabled to simulate the AS-203 experiment. Here, a free surface treatment is required to separate the liquid and gas phases. Surface tension although not dominant over buoyancy in the problem is enabled to capture any low-gravity interface motion accurately. Wall shear is also included in the model for natural convection velocity field prediction which is more significant in low gravity than in normal gravity or higher. The two-equation $k-\varepsilon$ model is used to predict the effects of turbulence on the natural convection boundary layers and mixing. Liquid density is allowed to vary with fluid temperature only but is incompressible with respect to pressure. The ullage region is modeled as a fully compressible ideal gas. Heat transfer between the liquid, gas, and tank walls is enabled to simulate the thermal stratification of the fluids. Finally, a modification to the commercially-available code is made to address phase change effects at the liquid-gas interface. For details of the formulations and assumptions within the FLOW-3D code see Ref. 12.

\section{B. Grid Sensitivity Study}

Too coarse of a computational mesh can influence the results in a nonphysical manner. A grid insensitive solution is derived by executing multiple simulations with various spatial resolutions to determine the largest, cell sizes that provide consistent results. A grid sensitivity study is an important, often overlooked aspect of model development that must be performed to ensure that the numerical discretization is not influencing the solution significantly. For the S-IVB model development six cases are run based on preliminary versions of the model to select an adequate mesh. The study considers test models with various total cell counts, axial cell sizes, radial cell 
sizes, and slosh baffle model formulation. The ullage pressure, ullage temperature, and liquid temperature are used to evaluate numerical mesh effects in the solutions. In Table 1 the computational grids and the results for each case are summarized. Here, $N_{X}$ is the number of $x$ cells, $\mathrm{N}_{Z}$ is the number of $\mathrm{z}$ cells, $\mathrm{N}_{\text {TOT }}$ is the total cell count, $\Delta \mathrm{X}$ is the smallest radial cell size, $t_{R U N}$ is the simulation run time, $P_{\text {ULLEND }}$ is the pressure at the end of the

\begin{tabular}{|c|c|c|c|c|c|c|c|c|c|}
\hline Mode! & Description & $\mathrm{N}_{\boldsymbol{x}}$ & $\mathrm{N}_{2}$ & $N_{\text {TOT }}$ & $\begin{array}{l}\Delta x \\
\text { (in) }\end{array}$ & $\begin{array}{l}t_{\text {Run }} \\
\text { (hrs) }\end{array}$ & $\begin{array}{l}\text { Pullend } \\
\text { (psia) }\end{array}$ & $\begin{array}{c}\text { TuLL,END } \\
\text { (R) }\end{array}$ & $\begin{array}{l}T_{\text {LLa,END }} \\
\text { (R) }\end{array}$ \\
\hline A & Initial Resolution & 40 & 100 & 4000 & 3.3 & 1.4 & 41.73 & 174.9 & 39.90 \\
\hline B & $\begin{array}{l}2.25 \times \text { Initial } \\
\text { Resolution }\end{array}$ & 60 & 150 & 9000 & 2.2 & 9.6 & 47.14 & 183.8 & 38.96 \\
\hline C. & $\begin{array}{l}0.25 \times \text { Initial } \\
\text { Resolution }\end{array}$ & 20 & 50 & 1000 & 6.6 & 0.1 & 26.3 & 120.3 & 39.33 \\
\hline D & $\begin{array}{l}0.56 \times \text { Initial } \\
\text { Resolution }\end{array}$ & 30 & 75 & 2250 & 4.4 & 0.5 & 36.64 & 141.6 & 40.11 \\
\hline E & $\begin{array}{l}1.56 \times \text { Initial } \\
\text { Resolution }\end{array}$ & 50 & 125 & 6250 & 2.6 & 3.8 & 44.93 & 174.6 & 39.59 \\
\hline . & $\begin{array}{c}\text { Initial Resolution } \\
\text { w/Baffle Fcns }\end{array}$ & 40 & 100 & 4000 & 2.6 & 1.5 & 38.68 & 172.9 & 38.59 \\
\hline
\end{tabular}

Table 1 Grid Sensitivity Study Results simulation, $T_{U L L, E N D}$ is the end ullage temperature, and $\mathrm{T}_{\mathrm{LIQ}, \mathrm{END}}$ is the predicted final temperature for the liquid. A description is also listed for each grid study case in Table 1 that indicates the relationship of the mesh to the initial 4000-cell case in model A.

All six models run successfully with no convergence issues and the simulation times on a $3.4 \mathrm{GHz}$ processor vary between 0.1 hours and 9.6 hours. The end ullage pressures range from 26 to 45 psia, the gas temperatures range from 120 to $184 \mathrm{R}$, and the liquid temperatures vary from 38.6 to $40.1 \mathrm{R}$. As observed the largest variations from model to model are in the ullage pressure and temperature. Figures 2 and 3 depict graphically the ullage pressure and temperature results as functions of total cell count. As observed in these plots both the pressure and temperature predictions become asymptotic for cell counts greater than the 4000 . Both models $A$ and $F$ have 4000 cells, and the difference between the models is in the slosh baffle and deflector approach. Model $F$ uses infinitely thin surfaces to represent the baffle and deflector where the other models use a much thicker formulation using FLOW-3D's obstacle functions. The infinitely thin baffle and deflector approach more accurately represents scale effects with respect to the natural convection boundary layers than the thicker obstacle-based method. Accordingly, due to diminished benefit for further resolution increase and a reasonable run time, the model $F$ grid is selected as the baseline for the S-IVB LH2 tank model.

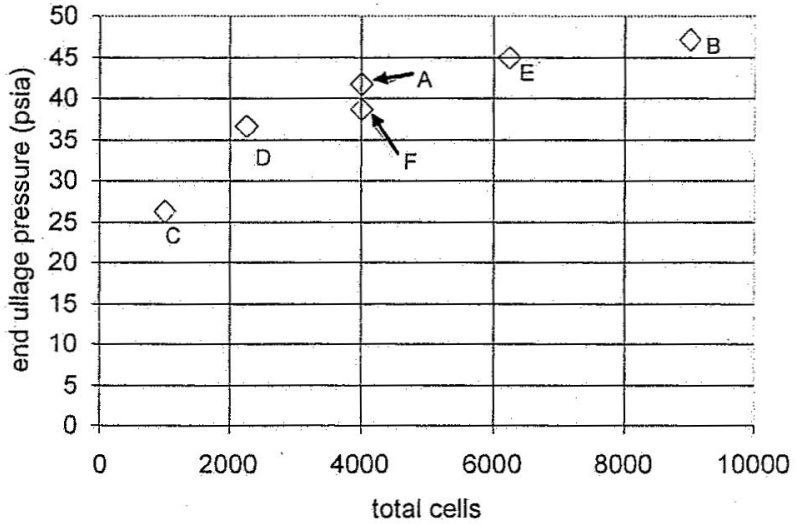

Figure 2 Pressure Sensitivity to Resolution

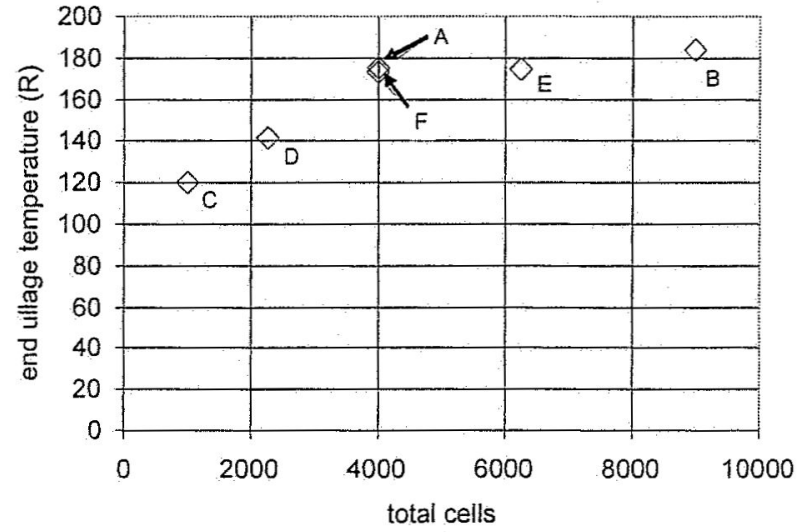

Figure 3 Temperature Sensitivity to Resolution

\section{S-IVB Model Description}

The derived baseline model for the S-IVB LH2 tank is illustrated in Fig. 4. The total domain includes 4000 computational cells in an axisymmetric arrangement. As shown the cavity is defined primarily by a cylindrical shell with a concave ellipsoidal forward dome and a convex aft bulkhead. The slosh baffle and deflector are conical in shape and are attached at the tank sidewall while the instrumentation rakes are neglected. The baffles in the model are sealed against the tank wall with no flow through area. They are simulated with FLOW-3D baffle functions that are infinitely thin barriers to flow located only at cell faces. The appearance is stair cased in shape since the baffles exist only on computational cell faces. Like in the actual vehicle design the slosh baffle is angled upward by 16 degrees and the deflector is angled downward by 17.5 degrees as shown in Fig. 4; they are located $1.6 \mathrm{ft}$ and $9.2 \mathrm{ft}$, 
respectively, above the free surface as measured at the wall. The initial liquid mass is $16000 \mathrm{lbm}$ with a liquid level just below the lower slosh baffle. In all analyses gas temperature is measured at $\mathrm{r}=5.5$ $\mathrm{ft}, \mathrm{z}=38.7 \mathrm{ft}$ where the bottom of the mesh is located at $\mathrm{z}=7.25 \mathrm{ft}$. Liquid temperature is measured at $\mathrm{r}=5.5 \mathrm{ft}, \mathrm{z}=17.2 \mathrm{ft}$. These are the same locations as physical temperature sensors in the actual flight test tank. Gas pressure in the model is recorded at the same place as the ullage temperature sensor.

The tank is initially quiescent with a uniform liquid hydrogen region saturated at $12.4 \mathrm{psia}$, as prescribed in the AS-203 experiment report in Ref. 1. The ullage gas region is reported to be superheated by $5 \mathrm{R}$ which is assumed to be at the top of the tank. Accordingly, the simulated ullage region is defined with an initial thermal stratification profile where the gas temperature is $35.5 \mathrm{R}$ near the liquid interface and $40.5 \mathrm{R}$ at the tank top. Separate wet side wall, dry side wall, upper dome, common bulkhead, and aft dome heat

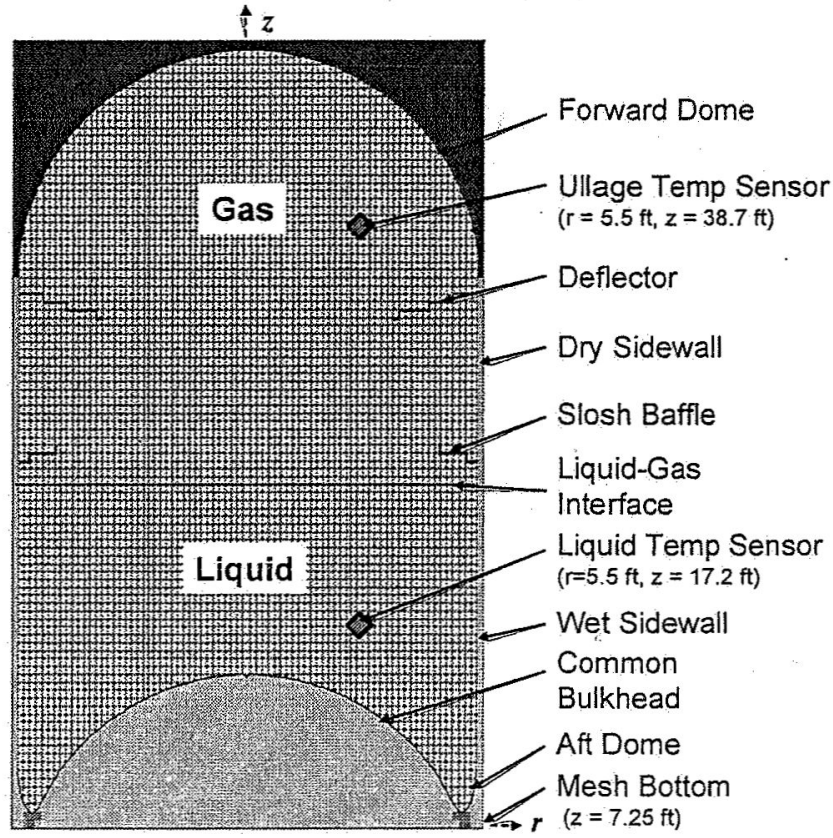

Figure 4 S-IVB Model Geometry and Mesh leak histories are applied in the model based on the calculated results in Ref. 1; see Fig. 5. The maximum energy flow rate into the tank is about 37,000 W.

During the closed tank experiment, the LH2 tank is locked up and allowed to pressurize, but the LO2 tank is continuously blowing down to generate a positive vehicle acceleration that maintains aft settled LH2. As with all blow-down systems the pressure and therefore the thrust decay with time. The accelerations measured with on-board accelerometers are applied to the entire CFD domain in the model. Only the axial acceleration is assumed significant, since the LO2 tank propulsive vents are aft facing. The measured acceleration history that is used in the

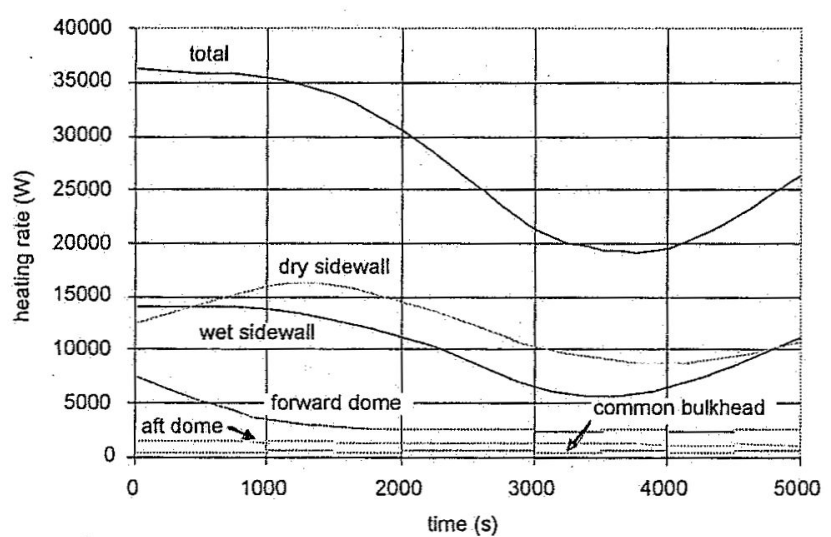

Figure 5 Tank Surface Heating Histories

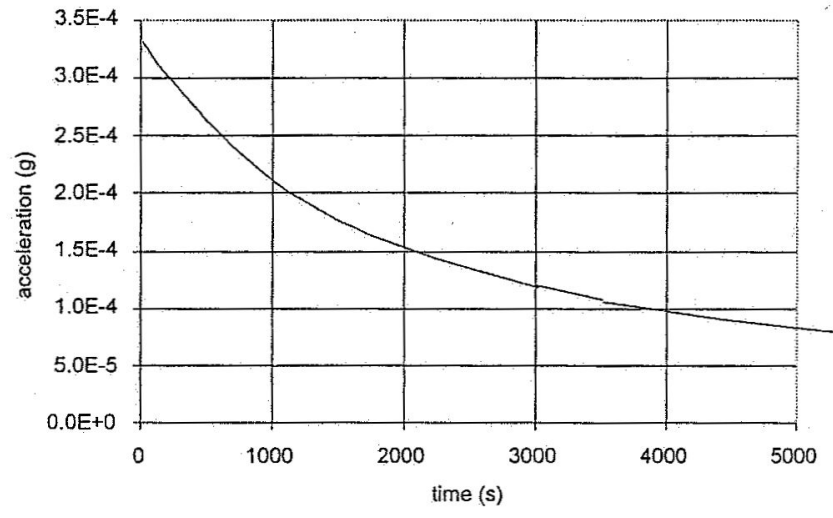

Figure 6 Axial Acceleration History

model is shown in Fig. 6.

\section{Results and Discussion}

The ullage pressure history graph from Ref. 1 is reproduced in Fig. 7 with the new CFD model prediction overlaid. The results from the CFD model are in general agreement with the test data where the average predicted pressurization rate is $17.6 \mathrm{psi} / \mathrm{hr}$ versus the $17.0 \mathrm{psi} / \mathrm{hr}$ rate that the test data suggests. The pressure error at the end of the experiment simulation is approximately $3.5 \%$ which is judged as good considering the approximate boundary conditions and other simplifying assumptions. The results in the present model are shown to be more accurate than the previous analytical attempts described in Ref. 1. Here, the Ref. 1 model with only liquid heating predicted an average pressurization rate that is significantly slower than the test data $(3.2 \mathrm{psi} / \mathrm{hr}$ model vs. $17.0 \mathrm{psi} / \mathrm{hr}$ test). 
Similarly, the Ref. 1 model that includes both ullage and liquid heating also produces too slow of a pressurization rate $(14.5 \mathrm{psi} / \mathrm{hr}$ model vs. $17.0 \mathrm{psi} / \mathrm{hr}$ test). The present CFD model, however, slightly over predicts the average pressurization rate $(17.6 \mathrm{psi} / \mathrm{hr}$ model vs. $17.0 \mathrm{psi} / \mathrm{hr}$ test), but is closer to the test data than either of the older two methods. The CFD pressure rise rate curve arches above the test data curve in the middle of the range, but then approaches the test data near the end of the experiment. It is mentioned that the test data curve from Ref. 1 is drawn based only on the eight test data points shown in Fig. 7. The gap in data is due to a gap in telemetry coverage during the flight, and accordingly, the tank pressure conditions during this blackout are not known with certainty. Hence the actual modeled and measured differences between 600 and 4300 seconds cannot be determined

The predicted ullage temperature history is also in good agreement with the measured test data as shown in Fig. 8. Here, the predicted and measured ullage temperatures are compared in the upper dome region. The

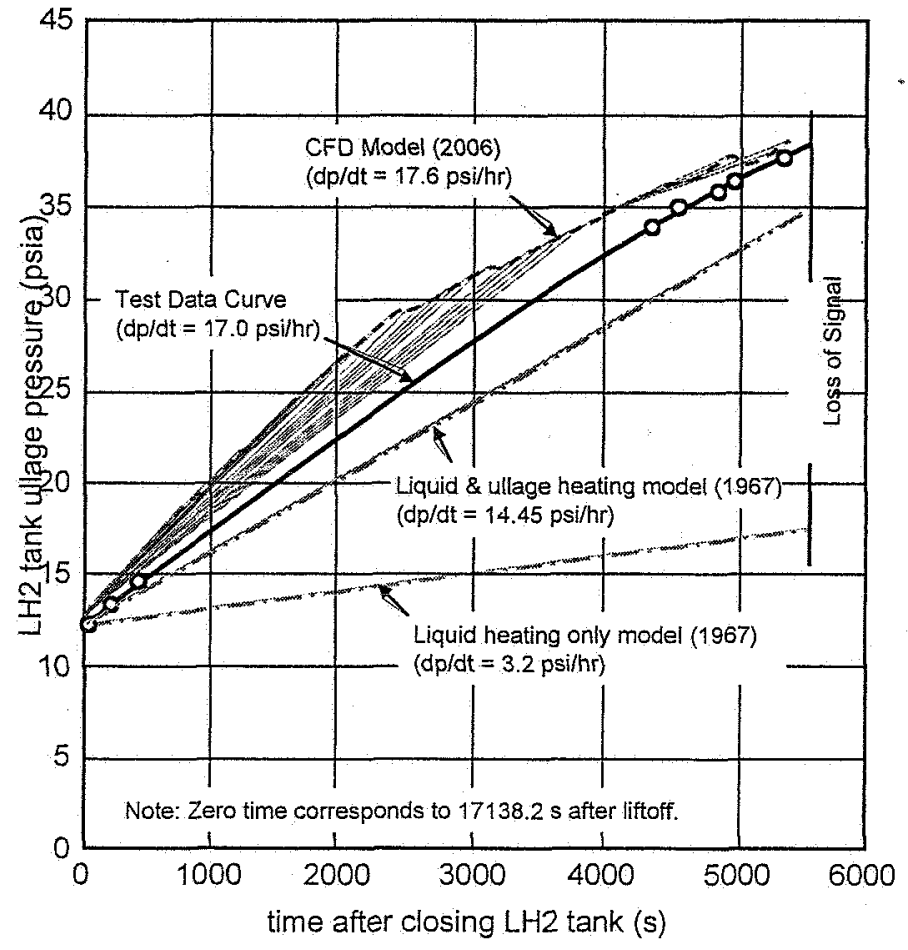

Figure 7 Predicted and Measured Ullage Pressure Histories model temperature rise rate follows the measured temperature trend well, but additional small fluctuations about the curve are predicted by the model. The liquid temperature generally follows the test trend, but also with temperature oscillations about the mean temperature rise rate curve as shown in Fig. 9. Here, the liquid temperature oscillations appear large due to the scale of the graph but are actually less than $1 \mathrm{R}$ in magnitude. Temperature fluctuations in the ullage and liquid can be explained by local convection and vortices that occur in the model.

In particular the baffles are shown to strongly influence the transport of energy from beneath the baffles to above the baffles. The series of temperature and velocity field plots in Fig. 10 illustrate the predicted motion within the tank during the experiment. The heated tank walls are shown to drive buoyant thermal boundary layers along the wet and dry sidewalls that transport warmed fluid toward the baffles. The deflector in the ullage region interrupts the boundary layer flow and diverts the moving gas toward the center of the tank. The warm gas travels around the deflector and forms large vortices in the upper dome ullage region. Pockets of warm ullage gas become trapped under the deflector that then spill inward towards the center of the tank; see Fig. 11. A second boundary layer above the deflector forms that continues to deposit warm gas in the top of the tank. It is noted that the dynamic effects of the baffles cause velocity disturbances on the same order of magnitude as the natural convection boundary layers. These motions are responsible for the oscillations in predicted ullage gas temperature. Although the gas temperature

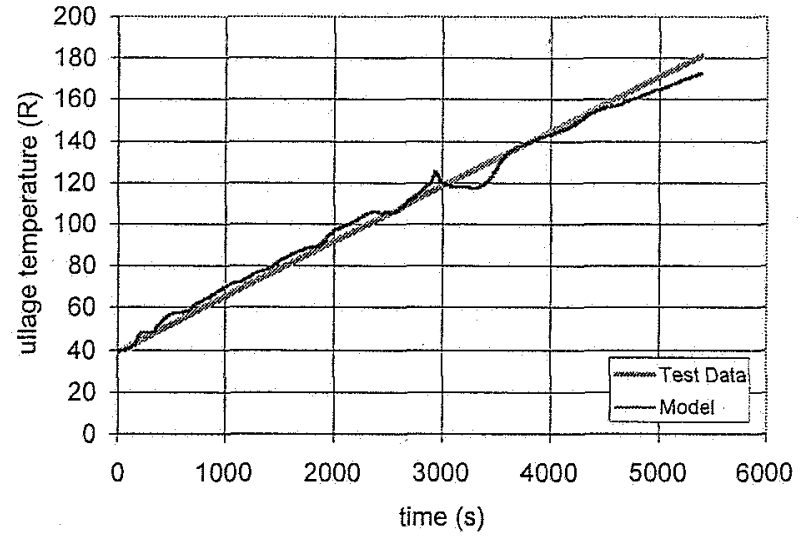

Figure 8 Predicted and Measured Ullage Temperature Histories

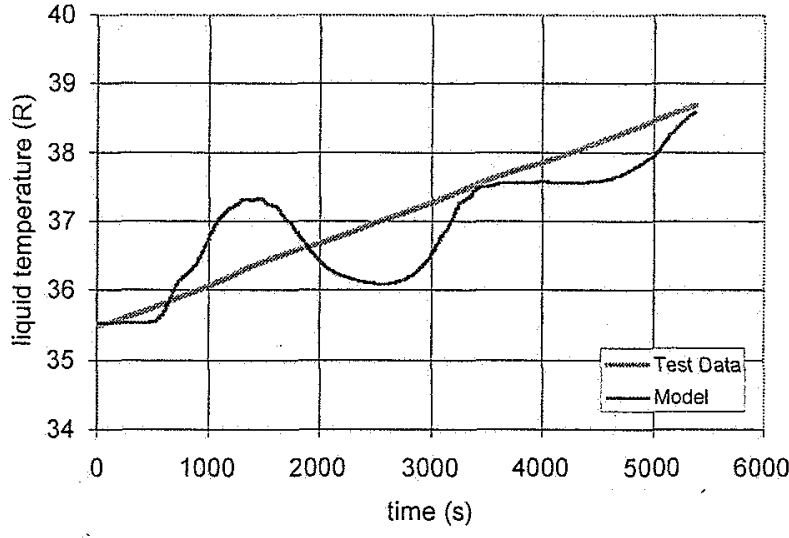

Figure 9 Predicted and Measured Liquid Temperature Histories 
predictions at the ullage sensor location are good, effects from the applied power boundary conditions are observed. Notice that the small region in the top $2.4 \mathrm{ft}$ of the tank becomes stratified by $273 \mathrm{R}$ with a peak temperature of 445 $R$ at the end of the simulation. It is unlikely that the top of the tank in the experiment actually reached $445 \mathrm{R}$ because the heating rate would have tapered off as the gas temperature next to the upper dome rose. No sensors are located in this region, so the actual temperature here is uncertain. Considering that the applied heating rates in the model are specified and not functions of local temperature, higher temperatures than reality are expected near the apex of the top dome. This effect is not significant to the overall tank pressure because the volume of this region is so small compared to the total tank. At the end of the simulation a stable, relatively flat low-gravity liquid-gas interface exists with thermal stratification in both the liquid and gas phases. Although the predicted local hot spots in the simulation are expected to be exaggerated, the model clearly indicates that even in a low-Earth orbit environment, natural convection can be a strong force within large cryogenic tanks.

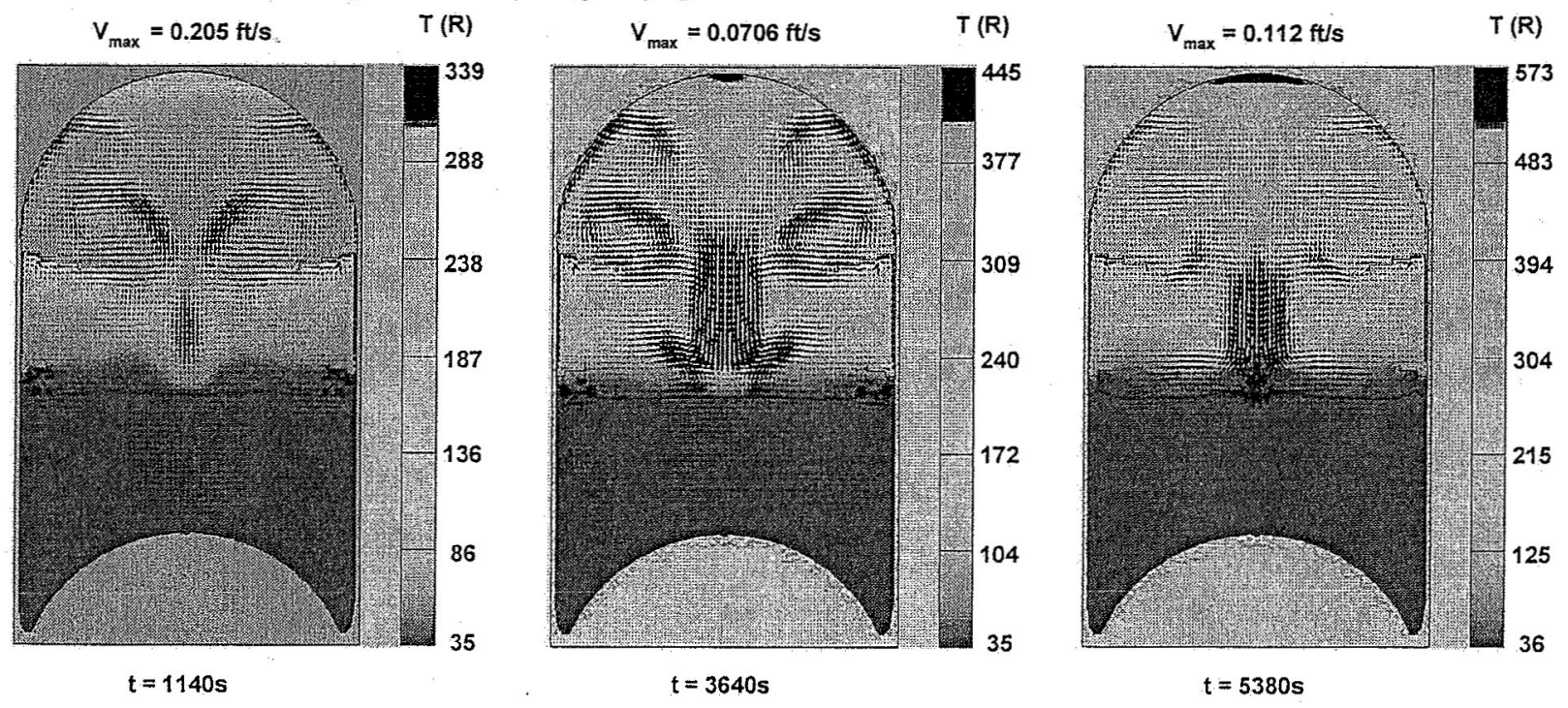

Figure 10 Temperature and Velocity Results

\section{Conclusion}

The developed CFD model of the Saturn S-IVB orbital experiment has been shown to predict cryogenic tank selfpressurization and thermal stratification with reasonably good accuracy. The average predicted ullage pressurization rate is within $3.5 \%$ of the pressure rise rate suggested by test data. Ullage temperature results are also in good agreement with the test data where the model predicts an ullage temperature rise rate within $6 \%$ of the data at the ullage sensor location. The model is based on first principles only and includes no adjustments to bring the predictions closer to the test data. Thus, first-time, experimental validation is achieved for a computational fluid dynamic modeling approach for cryogenic tanks in low-gravity. Much work of course remains if other salient propulsion system features such as liquid acquisition devices, thermodynamic vents, and noncondensable gases are to be accounted for accurately. It is noted that the S-IVB experiment did use a very large tank with a high heat leak and big ullage volume. Accurate modeling of low heat leak systems $(<100 \mathrm{~W})$ with small tanks and small ullage volumes

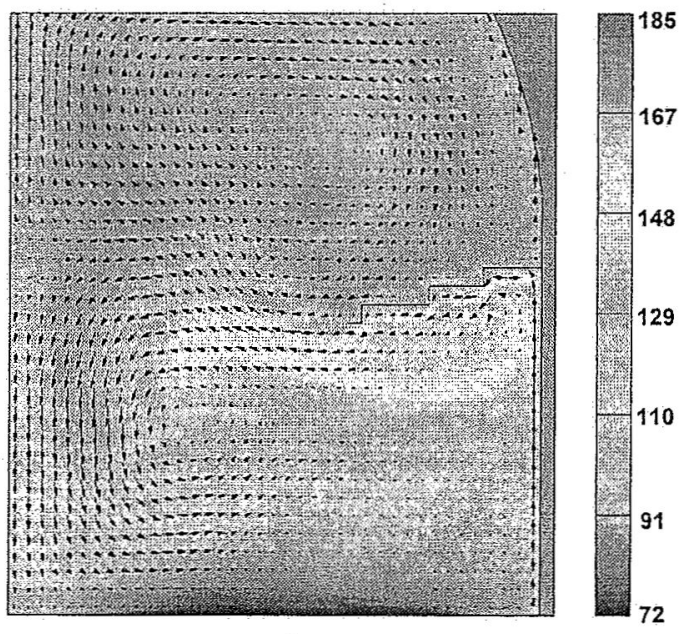

Figure 11 Temperature and Velocity at Upper Baffle remains to be demonstrated. However, this initial quantitative verification does, represent a significant step toward application of the developed methods to near term space-based cryogenic system design. Once developed and proven across a wide range of cryogenic engineering, CFD-based design processes will provide considerable cost savings over test-based development philosophies especially those requiring on-orbit cryogenic flight experiments. 


\section{Acknowledgments}

This work was supported by the NASA Marshall Space Flight Center under the Pressure Control Data Correlation contract NNM05AB18C.

\section{References}

${ }^{1}$ Ward, W.D., et al, "Evaluation of AS-203 Low-Gravity Orbital Experiment," NASA CR 94045 (Chrysler Corp. Space Div. Technical Report BB-3.4.3-5-101), 13 January 1967.

${ }^{2}$ Mikelis, N.E., Miller, J.K., and Taylor, K.V., "Sloshing in Partially Filled Liquid Tanks and its Effect on Ship Motions: Numerical Simulations and Experimental Verification," Royal Institution of Naval Architects, Spring Meetings, Paper No. 7, London, 1984.

${ }^{3}$ Sicilian, J.M. and Tegart, J.R., "Comparison of FLOW-3D Calculations with Very Large Amplitude Slosh Data," ASME Pressure Vessels and Piping Conference, Vol. 176, pp. 23-30, 1989.

${ }^{4}$ Fisher, M.F., Schmidt, G.R., and Martin, J.J., "Analysis of Cryogenic Propellant Behavior in Microgravity and Low Thrust Environments," AlAA Paper 91-2173, June, 1991.

${ }^{5}$ Grayson, G., and DiStefano, E., "Propellant Acquisition for Single-Stage Rocket Technology," 29th AIAA/SAE/ASME/ASEE Joint Propulsion Conference, Paper 93-2283, Monterey, CA, June 1993.

${ }^{6}$ Grayson, G.D., "A Coupled Fluid-Dynamic-Thermodynamic Solution of an Upper-Stage Liquid Hydrogen Tank," Journal of Spacecraft and Rockets, Vol. 32, No. 5, September 1995, pp. 918-921.

${ }^{7}$ Grayson, G.D., and Cook, L.M., "Characteristics of the DC-XA Liquid Oxygen Propellant-Acquisition System," 32nd AIAA/ASME/SAE/ASEE Joint Propulsion Conference, Paper 96-3081, Lake Buena Vista, Florida, July 1996.

${ }^{8}$ Grayson, G.D., Watts, D.A., and Jurns, J.M., "Thermo-Fluid-Dynamic Modeling of a Contained Liquid in Variable Heating and Acceleration Environments," 1997 ASME Fluids Engineering Division Summer Meeting, Paper 3567, Vancouver, Canada, June 1997.

${ }^{9}$ Grayson, G.D., "A Computational Design Methodology for Vane-Based Propellant-Acquisition Systems in Spacecraft and Launch Vehicles," Young Specialists Conference, Moscow, Russia, May 1998.

${ }^{10}$ Grayson, G.D., "A Conservative Approach for Estimation of Propellant Slosh Damping from Anti-Vortex \& Vapor-Ingestion-Suppression Devices," 2001 ASME Fluids Engineering Division Summer Meeting, Paper FEDSM2001-18029, New Orleans, LA, May 2001.

${ }^{11}$ Grayson, G.D., "Computational Design Approach to Propellant Settling," Journal of Spacecraft and Rockets, Vol. 40, No. 2, March 2003, pp. 193-200.

${ }^{12}$ FLOW-3D User's Manual, version 9.0, Flow Science, Inc., Santa Fe, NM 2005. 